2. Динамика некоторых биохимических показателей крови телят, больных субклиническим рахитом / В. А. Трушкин, И. В. Никишина, С. П. Ковалев [и др.] // Вопросы нормативно-правового регулирования в ветеринарии. - 2018. - № 1. - С. 70-72. 3. Клиническое значение показателей антиоксидантной системы организма собак с хронической болезнью почек / В. Н. Гапонова, С. П. Ковалев, В. А. Трушкин [и др.] // Вопросы нормативноправового регулирования в ветеринарии. - 2020. - № 1. - C. 183-185. - DOI 10.17238/issn20726023.2020.1.183.

4. Котова, А. В. Латинский язык в современном образовательном пространстве / А. В. Котова //
Современные направления развития науки в животноводстве и ветеринарной медицине: Материалы международной научно-практической конференции посвященной 60-летию кафедры Технологии производства и переработки продуктов животноводства и 55-летию кафедры Иностранных языков, Тюмень, 25 апреля 2019 года. - Тюмень: ФГБОУ ВО "Государственный аграрный университет Северного Зауралья", 2019. - С. 352-354.

5. PSXI-12 Effect of copper on aminotransferases serum activity in European carp / A. O. Taraskin, P. A. Polistovskaia, A. I. Enukashvili [et al.] // Journal of Animal Science. - 2020. - Vol. 98. - No S4. - P. 390. - DOI 10.1093/ jas/skaa278.687.

\title{
ANALYSIS OF INDICATORS OF LYSOZYME ACTIVITY OF BLOOD SERUM OF RAINBOW TROUT (ONCORHYNCHUS MYKISS) WHEN USING THE DRUG "SMARTBIOTIC"
}

\section{L.Yu. Karpenko' ${ }^{1}$, A.A. Bakhta ${ }^{1}$, K.P. Ivanova ${ }^{1}$, P.A. Polistovskayal, A.A. Pechenkina', V.B. Galetskiy', V.P. Rudyak} ('St. Petersburg State University of Veterinary Medicine, ${ }^{2} A O$ Gatchinsky KKZ, 'OOO'Lignohumat)'

Key words: rainbow trout, lysozyme activity, "SMARTBIOTIC", feed additives, fish farming.

In this study, to activate the humoral link of nonspecific resistance of the fish organism, as well as to stimulate growth and development, prevent infectious and invasive diseases, the drug "SmartBiotic" was used, which contains humic acids. The research was carried out on the basis of LLC "Lososevo - whitefish nursery" Kingisepsky district, Leningrad region, the village of Velkota, which is the largest nursery in the city of Kingisepp for breeding rainbow trout. For the study, three groups of underyearlings of the rainbow trout (Oncorhynchus mykiss) were formed. One group served as control, and the other two were experimental. The first experimental group of young of the year received the drug at a concentration of $0.15 \%$, and the second experimental group - at a dose of $0.25 \%$. In the control group of rainbow trout, SmartBiotic was not used. All three groups were formed using the analog pairing method and raised in three different pools. Blood serum samples were taken twice: before giving postbiotic and one and a half months after using the drug. In the blood serum of fish in all three groups, the lysozyme activity of blood serum was determined according to the generally accepted method.

\section{REFERENCES}

1. The activity of lysozyme was determined by the photoelectrocolometric method according to Dorofeichuk A.G. with a change in the temperature regime of the reaction of the blood serum of chickens with M. lisodecticus culture (Sadovnikov N.V., Pridybailo N.D., Vereshchak N.A., and Zaslonov.C. General and special methods of studying the blood of birds of industrial crosses./- Yekaterinburg - Saint Petersburg: Ural State Agricultural Academy, NPP "AVIVAK" 2009,. pp.18-19.). 2. Dynamics of some biochemical blood parameters of calves with subclinical rickets / V. A. Trushkin, I. V. Nikishina, S. P. Kovalev [et al.] // Issues of regulatory regulation in veterinary medicine. - 2018. - No. 1. - pp. 70-72. 3. Clinical significance of indicators of the antioxidant system of dogs with chronic kidney disease / V. N. Gaponova, S. P. Kovalev, V. A. Trushkin [et al.] // Issues of regulatory regulation in veterinary medicine. - 2020. -
No. 1. - pp. 183-185. - DOI 10.17238/issn20726023.2020.1.183.

4. Kotova, A.V. Latin language in the modern educational space / A.V. Kotova // Modern trends in the development of science in animal husbandry and veterinary medicine: Materials of the international scientific and practical conference dedicated to the 60th anniversary of the Department of Technology of Production and Processing of Animal Products and the 55th anniversary of the Department of Foreign Languages, Tyumen, April 25, 2019. - Tyumen: State Agrarian University of the Northern TransUrals, 2019. - pp. 352-354.

5. The effect of PSXI-12 copper on the activity of serum aminotransferases of European carp / A.O.Taraskin, P.A.Polistovskaya, A.I.Enukashvili [et al.]// Journal of Animal Science. - 2020. - Vol.98. - No. S4. - p.390- - DOI 10.1093/jas/skaa278.687.

\section{ДИНАМИКА ФРАКЦИЙ ХОЛЕСТЕРИНА У КОРОВ В ТРАНЗИТНЫЙ ПЕРИОД}

\author{
Васильева С.B., orcid.org/0000-0002-7324-6250 \\ (ФГБОУ ВО «Санкт-Петербургский государственный университет ветеринарной медицины»)
}

Ключевые слова: коровы, транзитный период, холестерин, липопротеины низкой плотности, липопротеины высокой плотности, $\beta$-гидроксимасляная кислота.

\section{PEФEPAT}

В данной статье описаны результаты исследования обмена холестерина у коров в транзитный период. Были подобраны коровы с оптимальной и повышенной упитанностью тела в сухостойный период за три недели до отёла. Забор крови проводили дважды до отёла и дважды после отёла через равные 
промежутки времени. В сыворотке крови исследовали концентрацию холестерина и его фракций - холестерина липопротеинов низкой плотности и липопротеинов высокой плотности, а также концентрацию $\beta$-гидроксимасляной кислоты на пятый день после отёла. Исследования показали однонаправленную динамику холестерина и его фракций в период наблюдения. Вначале определялось снижение всех показателей, минимальные значения выявлены в течение первой недели после отёла. К концу опыта все фракции холестерина возрастали. Было установлено, что у коров, имевших повышенную упитанность в сухостойный период, уровень холестерина ЛПНП в послеотёльный период был достоверно ниже на 19,0-25,4\%, чем у коров с оптимальной упитанностью. Также установлено, что у упитанных коров более активно идёт кетогенез через 5 дней после отёла. Так, у коров с повышенной и оптимальной упи-

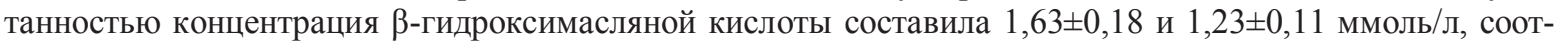
ветственно, что может свидетельствовать о наличии субклинического кетоза у ожиревших коров.

\section{ВВЕДЕНИЕ}

В организме животных холестерин выполняет различные функции, которые подразделяются на структурные и метаболические. Известно, что холестерин включён в состав билипидного слоя клеточных мембран и наряду с глицерофосфолипидами обуславливает особые их свойства - это сочетание прочности, эластичности и текучести $[5,6]$. Также холестерин является важным предшественником биологически активных веществ холекальциферола и стероидных гормонов, которые регулируют практически все виды обмена (углеводный, липидный, белковый, минеральный), а также репродуктивную функцию $[4,8]$. Желчные кислоты - холевая, хенодезоксихолевая - вырабатываются в печени из холестерина и являются конечными продуктами его метаболизма. Они, в конечном счёте, восстанавливаются до литохолевой кислоты, которая выводится из организма через кишечник. Перед тем, как эскретироваться из организма, желчные кислоты выполняют важную роль в пищеварении липидов: именно они осуществляют солюбилизацию жиров, превращая крупные липидные капли в тонкую эмульсию, обеспечивая тем самым максимальную биодоступность молекул для воздействия панкреатической липазы. В отношении липазы желчные кислоты проявляют действие активаторов профермента.

Холестерин может поступать в организм животного с кормами. В пищеварительном тракте с помощью эстераз осуществляется гидролиз сложноэфирной связи эфиров холестерина с жирными кислотами. Свободный холестерин абсорбируется в составе холеиновых комплексов и используется в организме для различных целей. Однако, не все виды животных могут получать экзогенный холестерин. Общеизвестно, что в растениях образуются фитостерины - ситостерин, эргостерин, стигмастерин и др., однако животный холестерин в них отсутствует [5]. Следовательно, растительноядные животные синтезируют холестерин de novo, тогда как хищники и всеядные получают его с кормами животного происхождения, а также синтезируют самостоятельно.

Источником для биосинтеза холестерина является молекула ацетил-КоА, которая у жвачных образуется из уксусной кислоты. Последняя яв- ляется продуктом рубцового пищеварения липолисахаридов и является количественно преобладающей в сравнении с другими летучими жирными кислотами.

Как известно, уксусная кислота преимущественно идёт на синтез молочного жира, а также вступает в реакции окислительного метаболизма.

Холестерин, циркулирующий в системном кровотоке, можно обнаружить в составе липопротеинов низкой (ЛПНП) и высокой (ЛПВП) плотности. Холестерин, образующийся в печени у коров, транспортируется в периферические ткани в составе ЛПНП, а удаляется из клеток в печень для превращения в желчные кислоты - в составе ЛПВП $[3,5,6]$. Помимо гепатоцитов практически все клетки способны к его синтезу. Предшественником для образования холестерина является ацетил-КоА, который может образовываться у коров непосредственно из ацетата, а также при окислении жирных кислот. Его биосинтез также тесно сопряжён с обменом углеводов, так как восстановительный эквивалент в виде НАДФ* $\mathrm{H}_{2}$, необходимый для ряда реакций данного процесса, образуется при пентозофосфатном окислении глюкозы [5].

Известно, что у коров после отёла довольно резко изменяется обмен веществ за счёт интенсификации лактогенеза, при этом активируется окислительный метаболизм в целом, а также обмен липидов. В этой связи интерес представляет анализ содержания фракций холестерина в крови коров при смене фаз физиологического цикла от сухостойного периода к лактации.

В задачу наших исследований вошло изучение динамики холестерина и его фракций в течение транзитного периода у коров.

\section{МАТЕРИАЛЫ И МЕТОДЫ}

Нами было проведено исследование коров в условиях животноводческого хозяйства «Осьминское» Ленинградской области. Было сформировано две группы животных в период сухостоя по 12 голов. Критерий формирования групп - упитанность на начало сухостойного периода. У коров первой группы упитанность свыше 3,75 баллов, у коров второй группы - 3,0 - 3,5 баллов. Кровь брали дважды до отёла (за 20-25 и 3-8 дней) и дважды - после отёла (через 3-7 и 15-20 дней). В сыворотке крови исследовали содержание общего холестерина, 
холестерина липопротеинов низкой плотности (ЛПНП) и холестерина липопротеинов высокой плотности (ЛПВП). У коров на пятый день после отёла проводили измерение $\beta$-гидроксимасляной кислоты в крови.

\section{РЕЗУЛЬТАТЫ И ОБСУЖДЕНИЕ}

Результаты исследования представлены в таблице 1.

Анализируя полученные результаты, можно отметить следующие тенденции: в обеих группах происходят однонаправленные изменения уровня общего холестерина и его фракций. Так, в течение транзитного периода происходит постепенное снижение всех исследуемых показателей до минимальных значений, которые определяются в ранний новотельный период. Затем, к концу периода наблюдения отмечается возрастание показателей. Динамика изменения холестерина отражает уровень энергетической обеспеченности организма коровы, поэтому снижение обменной энергии рационов в сухостойный период сопровождается уменьшением исследуемого показателя в крови. После отёла питательная ценность рационов значительно выше, чем в сухостойный период, но коровы не успевают быстро адаптироваться к более энергоёмкому питанию. Это связано с тем, что интенсивность пищеварительных процессов у жвачных напрямую зависит от деятельности рубцовой микрофлоры. Микробиота рубца после относительно бедного по ряду нутриентов сухостойного периода не успевает одномоментно возобновить свою популяцию в послеотёльный период, поэтому некоторое время корова недополучает необходимое количество питательных веществ. Этот период связан с временным отрицательным энергетическим балансом, который как правило заканчивается через 3-4 недели после отёла. В нашем исследовании коровы первой и второй групп к концу периода наблюдения показали тенденцию к возрастанию концентрации общего холестерина в крови на 33,0 и $38,4 \%$, соответственно $(\mathrm{P}<0,01)$, в сравнении с минимальными значениями в ранний новотельный период. При детальном рассмотрении фракций холестерина становится понятно, что наибольший вклад в восстановление уровня общего холестерина вносит возрастание содержание холестерина ЛПНП, который образуется в печени. Так, данный показатель увеличивается на $39,2 \%$ в первой группе и на $36,8 \%$ во второй группе. Тогда как увеличение фракции холестерина ЛПВП определяется в группах 1 и 2 на $36,3 \%$ и $21,2 \%$, соответственно. Однако при межгрупповом сравнении уровня холестерина ЛПНП после отёла показывает, что в первой группе этот показатель оказывается ниже на 19,0-25,4\% в сравнении с животными второй группы (в обоих случаях $\mathrm{P}<0,05)$. Это иллюстрирует снижение синтетической функции печени у коров, имевших в сухостойный период избыточную массу тела. Действительно, ожиревшие коровы имеют больше метаболических нарушений по сравнению с коровами нормальной упитанности $[1,2]$. Повышение липомобилизации после отёла приводит к перегрузке гепатоцитов триглицеридами и жирными кислотами, что отрицательно сказывается на метаболических реакциях в печени [3, 7, 9]. В наших исследованиях выявлено, что у упитанных коров более активно идёт кетогенез через 5 дней после отёла. Так, у коров группах 1 и 2 концентрация $\beta$-гидроксимасляной кислоты составила $1,63 \pm 0,18$ и $1,23 \pm 0,11$ ммоль/л, соответственно, что может свидетельствовать о наличии субклинического кетоза у коров первой группы. Реакции кетогенеза, также, как и биосинтез липопротеинов низкой плотности претекают в печению более того, у кетоновых тел и холестерина общий предшественник - ацетилКоА $[2,5]$, а также полностью совпадают первые реакции вплоть до образования молекулы $\beta$ гидрокси- $\beta$-метилглутарил-КоА, можно утверждать, что у коров с высокой упитанностью тканевая липомобилизация приводит к активации в большей степени кетогенеза, чем синтеза холестерина. При этом ещё одним неблагоприятным фактором является перегруженность печени липидами и ослабление биосинтеза липопротеинов.

\section{ЗАКЛЮЧЕНИЕ}

Проведённые исследования позволили сделать вывод, что коровы, имеющие избыточную упитанность в сухостойном периоде, после отёла имеют меньшие адаптационные способности по сравнению с коровами оптимальной кондиции. Как показали результаты эксперимента, у ожиревших коров в ранний новотельный период уменьшается способность печени к синтезу холе-

Таблица 1.

Динамика уровня холестерина и его фракций в течение транзитного периода

\begin{tabular}{|c|c|c|c|c|c|}
\hline \multirow{2}{*}{ Показатели } & \multirow{2}{*}{ Группы } & \multicolumn{2}{|c|}{ Срок до отёла } & \multicolumn{2}{|c|}{ Срок после отёла } \\
\cline { 3 - 5 } & & $20-25$ дней & $3-7$ дней & $3-7$ дней & $15-20$ дней \\
\hline Холестерин, ммоль/л & 1 группа & $3,27 \pm 0,16$ & $2,98 \pm 0,16$ & $2,61 \pm 0,16$ & $3,49 \pm 0,1633 \%$ \\
\cline { 2 - 5 } & 2 группа & $3,12 \pm 0,07$ & $2,92 \pm 0,15$ & $2,55 \pm 0,11$ & $3,53 \pm 0,1738,4 \%$ \\
\hline Холестерин ЛПНП, & 1 группа & $1,22 \pm 0,12$ & $1,02 \pm 0,08$ & $0,79 \pm 0,06^{*}$ & $1,10 \pm 0,06 * 39,2$ \\
\cline { 2 - 5 } ммоль/л & 2 группа & $1,25 \pm 0,05$ & $1,12 \pm 0,05$ & $0,94 \pm 0,03$ & $1,38 \pm 0,0746,8$ \\
\hline Холестерин & 1 группа & $1,92 \pm 0,12$ & $1,85 \pm 0,15$ & $1,54 \pm 0,13$ & $2,10 \pm 0,1436,3$ \\
\cline { 2 - 5 } ЛПВП, ммоль/л & 2 группа & $1,63 \pm 0,07$ & $1,51 \pm 0,11$ & $1,46 \pm 0,1$ & $1,77 \pm 0,1021,2$ \\
\hline
\end{tabular}


стерина ЛПНП, а также увеличивается продукция кетоновых тел.

\section{ЛИТЕРАТУРА}

1. Васильева, С.В. Сравнительные исследования важнейших показателей метаболизма у новотельных коров в различных хозяйствах в связи с данными по выбытию стада / С.В. Васильева // Вопросы нормативно-правового регулирования в ветеринарии, - 2020. - №4. - c.153-156. 2. Васильева, С. В. Влияние питательной ценности рационов на показатели метаболизма у лактирующих коров / С. В. Васильева // Материалы национальной научной конференции профессорско-преподавательского состава, научных сотрудников и аспирантов СПбГУВМ, Санкт-Петербург, 25-29 января 2021 года. - СанктПетербург: Санкт-Петербургский государственный университет ветеринарной медицины, 2021. - С. 20-22.

3. Душкин Е.В. Аккумуляция липидов в печени и кетоновых тел в крови у новотельных коров в зависимости от разного уровня кормления. // Материалы Международной научно-практической конференции «Актуальные вопросы аграрной науки и образования», посвященной 65-летию Ульяновской ГСХА. Ульяновск. - 2008. - Т. 3. - С. 32-35. 4. Карпенко Л.Ю. Сравнительная оценка динамики основных показателей метаболизма у коров с разной молочной продуктивностью / Л.Ю. Карпенко, Н.В. Пилаева, Р.М. Васильев, С.В. Васильева // Вопросы нормативно-правового регулирования в ветеринарии.
2018. № 3. C. 190-192.

5. Конопатов, Ю. В. Биологическая химия : учебное пособие / Ю. В. Конопатов, Л. Ю. Карпенко, С. В. Васильева ; Конопатов Ю. В., Карпенко Л. Ю., Васильева С. В.; Министерство сельского хозяйства РФ, Департамент научнотехнологической политики и образования, СанктПетербургская государственная академия ветеринарной медицины. - Санкт-Петербург : Санкт-Петербургская государственная академия ветеринарной медицины, 2015. - 296 с. 6. Показатели молочной продуктивности, триацилглицеролов в крови и печени в послеродовой период в зависимости от уровня рациона / В.А. Трофимушкин, Е.В. Душкин, Е.А. Кондратьева [и др.] // Эффективное животноводство. - 2015. - №9(118). - с. 15-18.

7. Показатели крови у больных кетозом коров / С. П. Ковалев, П. С. Киселенко, В. А. Трушкин, А. А. Никитина // Актуальные проблемы инновационного развития животноводства : Международная научнопрактическая конференция, Брянск, 30-31 мая 2019 года. - Брянск: Брянский государственный аграрный университет, 2019. - С. 86-89.

8. Dynamics of cholesterol and triglycerides in the serum of cows with liver lipidosis / K. Moiseeva, P. Anipchenko, S. Vasil'eva [et al.] // Journal of Animal Science. - 2019. Vol. 97. - No S3. - P. 208. - DOI 10.1093/jas/skz258.427. 9. The result of histochemical research in the diagnosis of steatosis in cows / A. Votinceva, A. Nikitina, G. Nikitin [et al.] // FASEB Journal. - 2019. - Vol. 33. - No S1. - P. 58.

\title{
DYNAMICS OF CHOLESTEROL FRACTIONS IN COWS DURING THE TRANSIT PERIOD
}

\author{
S.V. Vasilieva
}

(St. Petersburg state university of veterinary medicine)

Key words: cows, transit period, cholesterol, low density lipoproteins, high density lipoproteins, $\beta$-hydroxybutyric acid.

This article describes the results of a study of cholesterol metabolism in cows during the transit period. Cows were selected with optimal and increased body fatness during the dry period three weeks before calving. Blood samples were taken twice before calving and twice after calving at regular intervals. In the blood serum, the concentration of cholesterol and its fractions - low-density lipoprotein cholesterol and high-density lipoprotein - was studied, as well as the concentration of $\beta$-hydroxybutyric acid on the fifth day after calving. Studies have shown unidirectional dynamics of cholesterol and its fractions during the observation period. Initially, a decrease in all indicators was determined, the minimum values were found during the first week after calving. By the end of the experiment, all cholesterol fractions increased. It was found that in cows with increased body condition during the dry period, the level of LDL cholesterol in the post-calving period was significantly lower by $19.0-25.4 \%$ than in cows with optimal body condition. It was also found that in well-fed cows ketogenesis is more active 5 days after calving. Thus, in cows with increased and optimal fatness, the concentration of $\beta$ hydroxybutyric acid was $1.63 \pm 0.18$ and $1.23 \pm 0.11 \mathrm{mmol} / 1$, respectively, which may indicate the presence of subclinical ketosis in obese cows.

\section{REFERENCES}

1. Vasilyeva, S.V. Comparative studies of the most important indicators of metabolism in fresh cows in various farms in connection with data on herd retirement / S.V. Vasilyeva // Issues of legal regulation in veterinary medicine, - 2020. - №4. - p. 153-156.

2. Vasilieva, S. V. Influence of nutritional value of diets on metabolic parameters in lactating cows / S. V. Vasilyeva // Proceedings of the national scientific conference of the faculty, researchers and graduate students of St. Petersburg State University of Higher Medical Sciences, St. Petersburg, January 25-29, 2021 of the year. - Saint Petersburg: Saint Petersburg State University of Veterinary Medicine, 2021. - pp. 20-22.

3. Dushkin E.V. Accumulation of lipids in the liver and ketone bodies in the blood of fresh cows depending on different levels of feeding. // Materials of the International Scientific and Practical Conference "Topical Issues of Agrarian Science and Education" dedicated to the 65th anniversary of the Ulyanovsk State Agricultural Academy.
Ulyanovsk. - 2008. - T. 3. - S. 32-35.

4. Karpenko L.Yu. Comparative assessment of the dynamics of the main indicators of metabolism in cows with different milk productivity / L.Yu. Karpenko, N.V. Pilaeva, R.M. Vasiliev, S.V. Vasilyeva // Questions of legal regulation in veterinary medicine. 2018.No. 3.P. 190-192. 5. Konopatov, Yu. V. Biological chemistry: a textbook / Yu. V. Konopatov, L. Yu. Karpenko, SV Vasilyeva; Yu. V. Konopatov, L. Yu. Karpenko, S. V Vasilyeva; Ministry of Agriculture of the Russian Federation, Department of Science and Technology Policy and Education, St. Petersburg State Academy of Veterinary Medicine. - St. Petersburg: St. Petersburg State Academy of Veterinary Medicine, 2015 .-- 296 p. 6. Indicators of milk productivity, triacylglycerols in the blood and liver in the postpartum period depending on the level of the diet / V.A. Trofimushkin, E.V. Dushkin, E.A. Kondratyev [et al.] // Effective animal husbandry. - 2015. No. 9 (118). - With. 15-18.

7. Blood indices in cows with ketosis / S. P. Kovalev, P. S. Kiselenko, V. A. Trushkin, A. A. Nikitina // Actual prob- 
lems of innovative development of animal husbandry: International Scientific and Practical Conference, Bryansk, 30- May 31, 2019. Bryansk: Bryansk State Agrarian University, 2019 .- pp. 86-89.

8. Dynamics of cholesterol and triglycerides in the serum of cows with liver lipidosis / K. Moiseeva, P. Anipchenko,
S. Vasil'eva [et al.] // Journal of Animal Science. - 2019. Vol. 97. - No S3. - P. 208. - DOI 10.1093/jas/skz258.427. 9. The result of histochemical research in the diagnosis of steatosis in cows / A. Votinceva, A. Nikitina, G. Nikitin [et al.] // FASEB Journal. - 2019. - Vol. 33. - No S1. - P. 58.

DOI: $10.52419 /$ issn2072-6023.2021.4.146

\title{
ОСОБЕННОСТИ ХОДА И ВЕТВЛЕНИЯ ЧРЕВНОЙ АРТЕРИИ КОШКИ ДОМАШНЕЙ
}

\author{
Прусаков А.В., Яиин А.В. \\ (ФГБОУ ВО «Санкт-Петербургский государственный университет ветеринарной медииины»)
}

Ключевые слова: чревная артерия, желудок, поджелудочная железа, печень, кровоснабжение, ангиология, кровеносная система.

\begin{abstract}
РЕФЕРAT
Заболевания органов пищеварения у животных встречаются достаточно часто. На их долю приходится от 40,0 до 50,0 процентов от всех болезней, имеющих незаразную патологию. Оценка возможных последствий, указанных выше патологических процессов, а также назначение адекватного лечения крайне затруднительно без четких знаний особенностей кровоснабжения внутренних органов. В связи с изложенным, целью исследование является установление особенностей хода и ветвления чревной артерии у кошки домашней. Материалом для проведения исследования послужили трупы десяти кошек в возрасте от восьми до двенадцати лет, исключая кошек породы мейн-кун. Исследование проводили с использованием метод вазорентгенографии. Инъекцию сосудистого русла проводили через брюшную аорту по общепринятой методике. Инъекционную массу изготавливали по прописи: 1 часть сурика свинцового, 8 частей скипидара живичного, 2 части глицерина. После коагуляции инъекционной массы путем проведения тонкого анатомического препарирования из трупа извлекали органокомплекс, включающий: желудок с конечной частью пищевода и начальной частью двенадцатиперстной кишки, поджелудочную железу и печень. Рентгеновскую съемку полученных препаратов осуществляли при следующих технических условиях: сила тока - 50 мА; напряжение на трубке - 35 кВ; фокусное расстояние до 50-60 см; экспозиция - до 1,5-3,0 секунд. Цифровую обработку полученных снимков с целью определения морфометрических параметров осуществляли при помощи программного обеспечения RadiAnt DICOM Viewer. Установили, что чревная артерия у кошки домашней несет артериальную кровь к желудку, печени и поджелудочной железе. На своем пути она дает начало селезеночной, левой желудочной и общей печеночной артерии, которые множественно ветвясь формируют ряд внутрисистемных анастомозов, образующих пути коллатерального кровотока вышеперечисленных органов.
\end{abstract}

\section{ВВЕДЕНИЕ}

В силу анатомо-физиологических особенностей болезни органов пищеварения у животных встречаются достаточно часто. На их долю в среднем приходится от 40,0 до 50,0 процентов от всех болезней, имеющих незаразную патологию. Установлено, что у мелких домашних животных чаще всего они возникают в следствии неправильного кормления. При этом, в первую очередь страдают крупные застенные пищеварительные железы - печень и поджелудочная железа. Помимо этого, в практике ветеринарного врача нередко встречаются случаи проглатывания мелкими домашними животными инородных предметов. Наличие последних в пищеварительном канале часто приводит к обтурациям, взывающим воспаление и некроз его отдельных участков $[1,2]$. Оценка возможных последствий, указанных выше патологических процессов, а также назначение адекватного лечения крайне затруднительно без четких знаний структурных особенностей кровоснабжения органов пищеварения. В доступных источниках литературы мы встретили усредненные сведенья по интересующей нас проблеме $[3,4]$. Учитывая вышеизложенное, мы поставили цель - установить особенности хода и ветвления чревной артерии у кошки домашней.

\section{МАТЕРИАЛ И МЕТОДЫ}

Материалом для проведения исследования послужили трупы десяти кошек в возрасте от восьми до двенадцати лет, исключая кошек породы мейн-кун. У всех исследуемых животных при жизни исключали болезни органов пищеварения. С целью установления особенностей хода и ветвления краниальной брыжеечной артерии использовали метод вазорентгенографии. Инъекцию сосудистого русла проводили через брюшную аорту по общепринятой методике. Инъекционную массу изготавливали по прописи: 1 часть сурика свинцового, 8 частей скипидара живичного, 2 части глицерина. После коагуляции инъекционной массы путем проведения тонкого анато- 